\title{
Familial localized scleroderma with paediatric onset: a review
}

\author{
Ida Yurtsever ${ }^{1}$, Małgorzata Łukomska', Piotr Sobolewski², Elżbieta Szymańska², Witold Owczarek², Irena Walecka
}

\begin{abstract}
1Department of Dermatology, Central Clinical Hospital of the Ministry of the Interior, Warsaw, Poland
${ }^{2}$ Centre of Postgraduate Medical Education in the Department of Dermatology, the Central Clinical Hospital of the Ministry of the Interior, Warsaw, Poland

${ }^{3}$ Department of Dermatology, Central Clinical Hospital of the Ministry of National Defence, Military Institute of Health Services, Warsaw, Poland

Adv Dermatol Allergol 2021; XXXVIII (2): 193-197

DOI: https://doi.org/10.5114/ada.2021.106195
\end{abstract}

\begin{abstract}
Localized scleroderma is an inflammatory disease causing sclerosis of the skin. The aetiology and pathogenesis of localized scleroderma remain unclear. Localized scleroderma is considered a genetically driven disease. It is not well understood if genetic factors or environmental exposure individually can cause its development or if their interaction is needed to trigger the disease. Some authors postulate that familial clustering is evidence of a hereditary disease. Familial localized scleroderma has been rarely reported and is a case worth studying. We present the review of literature on this subject with 3 additional cases of familial localized scleroderma with paediatric onset.
\end{abstract}

Key words: morphea, localized scleroderma, familial, paediatric onset, juvenile.

\section{Introduction}

Localized scleroderma is an inflammatory disease causing sclerosis of the skin. The aetiology and pathogenesis of localized scleroderma remain unclear. Localized scleroderma is considered a genetically driven disease. It is not well understood if genetic factors or environmental exposure individually can cause its development or if their interaction is needed to trigger the disease. Some authors postulate that familial clustering is evidence of a hereditary disease. Familial localized scleroderma has been rarely reported and is a case worth studying. We present the review of literature on this subject with 3 additional cases of familial localized scleroderma with paediatric onset.

\section{Database}

We searched databases (PubMed, MedLine, Elsevier) with key words: 'morphea', 'localized scleroderma', 'familial', 'paediatric onset', 'juvenile', and 'hereditary' reviewing all available publications of familial cases of localized scleroderma.

\section{Pathogenesis}

Localized scleroderma is an inflammatory sclerosing disease of the dermis and subcutaneous tissue with multiple clinical subtypes. The course of the disease may vary, starting with slight erythematous superficial sclerosis of the skin to more severe cases with a decreased quality of life due to pain, skin thickness, as well as muscle and joint involvement [1, 2]. Outcome of paediatric-onset localized scleroderma is worse than in adult-onset one because of longer duration, more frequent involvement of deeper and extracutaneous tissues and delayed introduction of treatment $[1,3,4]$. Although the aetiology and pathogenesis of morphea remain unknown, autoimmune, environmental, and infectious factors have been proposed [1, 5].

The prevalence of autoantibodies in morphea and the general population is usually the same, but anti-single strand DNA, fibrillin-1, histone and topoisomerase II antibody titre may increase in morphea and antinuclear antibody titre in linear or generalized morphea $[1,4,6,7]$.

Vascular changes and imbalance between collagen destruction and production are components of sclerosis of the skin. Elevated vascular endothelial growth factor is evidence

Address for correspondence: Prof. Witold Owczarek PhD, MD, Department of Dermatology, Central Clinical Hospital of the Ministry of National Defence, Military Institute of Health Services, 128 Szaserów St, 04-141 Warsaw, Poland, phone: +48 261816241 , fax: +48 261817 187, e-mail: witold.owczarek@dermedicus.pl Received: 3.02.2020, accepted: 15.04.2020. 
of vascular damage. An activation of T-cell derived cytokines (interleukin-4, -6, -8, -10, -13, and -17, TGF- $\beta$, PDGF, endothelin-1) and fibroblasts cause abnormal collagen synthesis $[2,4,8]$. There are also well-known suppressors of collagen production for example $\alpha$ and $\gamma$ interferon, both of which are produced by Th1 lymphocytes. STAT4 factors (responsible for Th1 differentiation) polymorphism are connected to increased susceptibility of localized scleroderma. There were several genome-wide association studies performed to delineate the genetic susceptibility factor [9-11].

\section{Hereditary disease?}

Studies involving genome-wide association have been performed in large multinational patient cohorts. In one U.S. study, the relative risk of inheriting localized scleroderma was at a rate of $<2 \%$ compared with $<0.1 \%$ in the general population [5]. 10-30\% of patients reported having a family history of autoimmune disease [7].

The candidate gene for inheritance susceptibility is expected to have single nucleotide change (single nucleotide polymorphisms (SNPS)). The dominant region associated with localized scleroderma is a major histocompatibility complex. HLA class I and class II alleles are linked to the development of localized scleroderma, although in familial cases there is no common HLA haplotype in affected individuals in different families [2, 8]. Within families, patients with morphea share at least one HLA haplotype and other family members with identical HLA haplotypes did not develop disease $[1,12]$. The MHC gene is necessary but not sufficient to induce disease, and that environmental triggering factors may be implicated $[1,13,14]$. The role of the genetic factor has been supported by cytogenetic demonstration of chromosome breaks and increased ice frequencies resulting from aberrant DNA reparation process [15].

Other non-HLA genes which are likely factors in the pathogenesis of the disease are: the protein tyrosine phosphatase nonreceptor 22 (PTPN22), interleukin (IL)-1 $\beta$ and NLRP1, interferon regulatory factor 5 (IRF5), and a transcription factor in the Toll-like receptor (TLR) [16-18]. Additionally, the downregulation of microRNA let-7a is thought to contribute to the excessive production of collagen in localized scleroderma [14].

Nonhereditary factors play a major role in the pathogenesis of the disease. Trauma is the most common trigger, reported in 7.3-11.8\% of patients [11]. Other events, such as B. burgdorferi infection, injury or inflammation of the affected area were revealed to be triggering factors [19-21]. Furthermore, hazards such as vinyl chloride, organic solvents,

Table 1. Reported cases of familial localized scleroderma

\begin{tabular}{|c|c|}
\hline Author and year of publication & Descrription \\
\hline Rees et al., 1953 [22] & Localized scleroderma in the father and daughter \\
\hline Christianson et al., 1956 [23] & $\begin{array}{l}\text { Familial occurrence of localized scleroderma in three families, one of them with three family members } \\
\text { affected }\end{array}$ \\
\hline Burge et al., 1968 [16] & Two sisters with childhood onset localized scleroderma \\
\hline Szczepanski et al., 1972 [24] & Localized scleroderma in 2 sisters \\
\hline Wuthrich et al., 1975 [2] & $\begin{array}{l}\text { Two familial cases of localized scleroderma. Histopathologically confirmed morphea in } 3 \text { siblings } \\
\text { of first family, and } 2 \text { siblings in second }\end{array}$ \\
\hline Taj et al., 1977 [25] & Identical morphea lesions of the hands of a 13year-old brother and an 11-year- old sister \\
\hline Kulin et al., 1986 [8] & $\begin{array}{l}\text { A family (father and child) with childhood onset of hypotrichosis and morphea with apparent } \\
\text { autosomal dominant inheritance }\end{array}$ \\
\hline Wadud et al., 1989 [26] & Clinically and histologically established localised scleroderma in 2 family members \\
\hline Bunker et al., 1990 [15] & 39-year-old mother and a 16-year-old daughter with childhood onset morphea lesions \\
\hline Kaur et al.,1993 [14] & Case of familial linear scleroderma in the mother and daughter. First case in Indian literature \\
\hline Manolios et al., 1996 [27] & 5 familial cases of scleroderma, 1 of the families affected with morphea \\
\hline Patrizi et al., 2000 [19] & Atrophoderma Passini-Pierini in 3 siblings \\
\hline De Keyser et al., 2000 [17] & $\begin{array}{l}\text { Familial scleroderma in } 2 \text { monozygotic twin pairs. The first twin pair was diagnosed with the systemic } \\
\text { form of scleroderma, the second pair with the localized form }\end{array}$ \\
\hline Iranzo et al., 2001 [13] & $\begin{array}{l}\text { Clinically and histologically established scleroderma en coup de sabre in a } 14 \text {-year-old girl and her } \\
\text { grandfather }\end{array}$ \\
\hline Brownell et al., 2007 [10] & 32-year-old woman and her 35-year-old sister presented with plaques of scleroderma en coup de sabre \\
\hline Pham et al., 2010 [28] & Plaque type morphea affecting a 9-year-old boy and his father \\
\hline Lis-Święty et al., 2014 [11] & $\begin{array}{l}\text { 20-year-old female monozygotic twins who presented with co-existence of lichen sclerosus } \\
\text { and localized scleroderma. Skin lesions typical for localized scleroderma occurred in both patients, } \\
\text { at the age of } 10\end{array}$ \\
\hline
\end{tabular}


polymerizing epoxy resins, bleomycin and silica have been reported to trigger scleroderma-like disorders [9].

Some authors postulate that we can consider familial clustering as evidence of a hereditary disease. A small number of familial localized scleroderma cases have been reported (Table 1) [22-28]. In 1953 Rees and Bennett documented the first familial case, which involved a father and daughter [19]. Since then, there have been more cases of familial morphea documented (Table 1). And there are more cases presented every year.

The rising number of familial cases reported suggests that the genetic component may predispose individuals to develop morphea.

This is another report to be added to literature: $2 \mathrm{sib}$ lings with deep morphea and their second cousin with deep linear scleroderma.

\section{Patient 1}

A 19-year-old female, diagnosed with deep morphea at the age of 3. Histopathology confirmed the diagnosis. The disease started as deep sclerosing focusing on the right thigh in 1999. It then progressed in 2014, when a new focus appeared on the chest. Currently, physical examination has revealed 2 deep, sclerosing foci involving the deep dermis and subcutaneous fat. Skin lesions involve the right hip, the thigh $(15 \times 7 \mathrm{~cm}, 5 \mathrm{~cm}$ deep) (Figure $1 \mathrm{~B})$ and chest in the region of the xiphoid process $(10 \times 8 \mathrm{~cm}, 2 \mathrm{~cm}$ deep) (Figure $1 \mathrm{~A}$ ). No other complaints have been reported. No irregularities, except for Jo-1 antibody titre elevation, were revealed in the antibody profile. An X-ray, USG of the abdomen and echocardiography did not reveal any abnormalities. Since 2014 the patient has been treated with rheological treatment, i.e. alprostadil administered intravenously at the daily dose of $60 \mathrm{mg}$ for 3 consecutive days given every 6 weeks, 500 lipoprotein lipase releasing units (LSU) of oral sulodexide (daily) and a topical treatment with heparinoid with good result. Due to the progress of morphea, the therapy with methotrexate was initiated in mid-2016 (primarily $20 \mathrm{mg}$ per week, then reduced to $15 \mathrm{mg}$ weekly in 2017) resulting in substantial improvement of the clinical course.
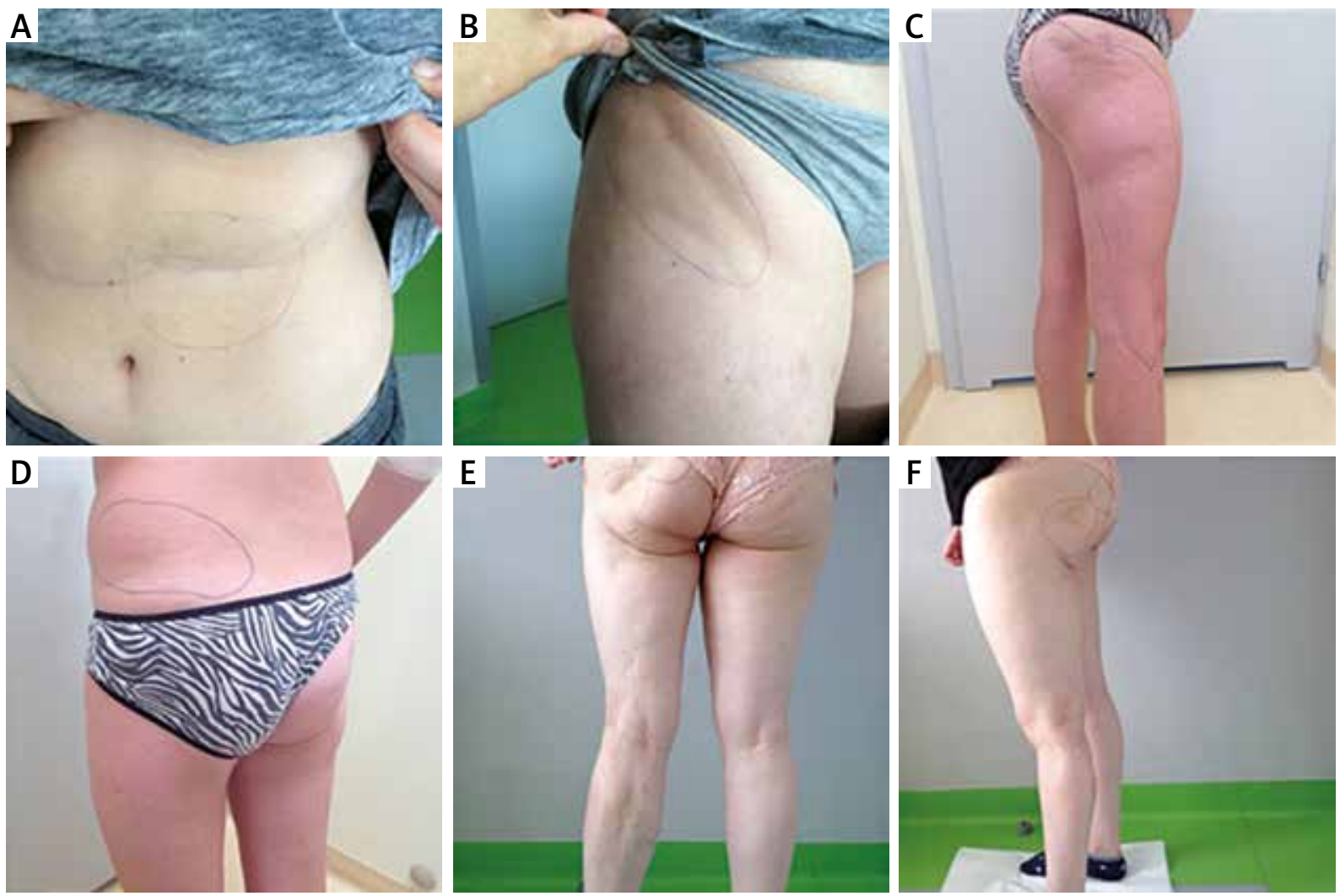

Figure 1. A - Clinical manifestation of the disease in patient 1. Clinical manifestation of the disease in patient 1. Visible deep, sclerosing involvement of the chest in the region of the xiphoid process $(10 \times 8 \mathrm{~cm}, 2 \mathrm{~cm}$ deep). B - Clinical manifestation of the disease in patient 1 . Visible deep, sclerosing focus of the right hip, the thigh $(15 \times 7 \mathrm{~cm}, 5 \mathrm{~cm}$ deep $)$ involving deep dermis and subcutaneous fat. C - Clinical manifestation of the disease in patient 2. Skin and subcutaneous sclerosis of the lateral area of the right thigh, the right popliteal fossa, as well as the medial and lateral areas of the right crus. D - Clinical manifestation of the disease in patient 2. Visible deep, sclerosing focus of the lumbar area involving deep dermis and subcutaneous fat. E, F - Clinical manifestation of the disease in patient 3. Visible sclerosis of the posterior crus with dyspigmentation and subcutaneous atrophy, involving the Achilles ligament, expanding to the left thigh, with atrophy of the muscles, especially deep atrophy of the left gluteal muscle 


\section{Patient 2}

A 14-year-old female, the sister of patient 1, who developed deep morphea in 2014, probably after a tick bite (Lyme disease was excluded). The disease started as sclerosis of a $5 \times 5 \mathrm{~cm}$ area of the right posterior thigh. Currently, skin and subcutaneous sclerosis are present in the lumbar area, lateral area of the right thigh, the right popliteal fossa as well as the medial and lateral areas of the right crus (Figures 1C, D). A biopsy revealed histopathological features of morphea. Antinuclear antibodies in high titre have been present. ENA-8 profile did not reveal a significant elevation of antibody titres. USG of the abdomen revealed no abnormalities. An echocardiography revealed a mild retrograde wave, requiring an annual cardiological check-up. Since 2014, the girl has been treated in the exactly same manner as her sister (patient 1), i.e. a combination of intravenous alprostadil, oral sulodexide and a topical heparinoid achieving good clinical outcome. In mid-2014 progress of the disease was observed, then $10 \mathrm{mg}$ of methotrexate weekly has been initiated with good result. The dose of methotrexate was increased in late 2017 up to 15 mg per week due to lack of satisfactory response and disease progression. Further remission of skin lesions was observed.

\section{Patient 3}

A 31-year-old female, and second cousin to Patient 1 and 2, was diagnosed with deep linear scleroderma in 1995 (at the age of 7). Skin lesions, which first appeared as a slight dyspigmentation at the posterior crus, developed as sclerosis of the posterior crus with dyspigmentation and subcutaneous atrophy, involving the Achilles ligament, expanding to the left thigh, with atrophy of the muscles; especially deep atrophy of the left gluteal muscle (Figures 1 E, F). Histopathology revealed thick crowded collagen bundles. Antinuclear antibodies, ENA-8 profile antibodies and anti-dsDNA antibodies were absent. Early and late R loops, meandering loops, capillary disorganizations and avascular fields were revealed in capillaroscopy. The USG performed within the skin lesions revealed dermal atrophy and an increase of echogenicity. The patient was treated with procaine penicillin in 1995, penicillamine and piascledine in 1996, penicillamine and chloroquine in 1997, and hydroxychloroquine in 1998 with no satisfying results. PUVA therapy was initiated in 2000 and continued until 2003 resulting in substantial improvement of the skin lesions. Calcineurin inhibitor monotherapy (0.1\% tacrolimus ointment) was applied until 2008. In 2008, due to the disease progression, PUVA therapy was reintroduced and continued until 2009 and then in 2011. Since 2011 no further exacerbation of the morphea course has been reported.

\section{Conclusions}

Based on epidemiological, genetic, familial, and twin studies we might assume that scleroderma is not a heri- table disease but may arise in genetically susceptible individuals when exposed to environmental triggers. Yet the growing number of familial cases might lead to the conclusion that localized scleroderma has multifactorial, polygenic inheritance.

As the cause of localized scleroderma as well as the contributing genetic and environmental factors were neither completely understood, nor properly studied it would be beneficial to determine if there are more frequent cases of familial morphea and if heredity should be taken into consideration for this disease. This review should be understood as an introduction and could lead to further studies involving more patients. Finding more cases of familial localized scleroderma and performing genetic examinations would contribute to the full understanding of this problem.

\section{Conflict of interest}

The authors declare no conflict of interest.

\section{References}

1. Li SC, Zheng RJ. Overview of Juvenile localized scleroderma and its management. World J Pediatr 2020; 16: 5-18.

2. Wuthrich RC, Henry HR, Willard DS. Localized scleroderma: a report of two families. Arch Dermatol 1975; 111: 98-104.

3. Condie D, Grabell D, Jacobe H. Comparison of outcomes in adults with pediatric-onset morphea and those with adultonset morphea: a cross-sectional study from the morphea in adults and children cohort. Arthritis Rheumatol 2014; 66: 3496-504.

4. Do N, Ringold S, Sullivan E, Brandling-Bennett H. A retrospective study: impact of consensus treatment plans on systemic therapy of pediatric morphea. Pediatr Dermatol 2020; 37: 278-83.

5. Varga J. Etiology and pathogenesis of scleroderma. In: Kelley's Textbook of Rheumatology. Firestein G, Budd R, Gabriel SE, et al. (eds). Elsevier 2013; 1343-61.

6. Jacobe H, Arnett FC, Reveille JD. Major histocompatibility, complex class I and class II alleles may confer susceptibility to or protection against morphea: findings from the Morphea in Adults and Children cohort. Arthritis Rheumatol 2014; 66: 3170-7.

7. Torok KS, Li SC, Jacobe HM, et al. Immunopathogenesis of pediatric localized scleroderma. Front Immunol 2019; 10: 908.

8. Kulin P, Sybert VP. Hereditary hypotrichosis and localized morphea: a new clinical entity. Pediatr Dermatol 1986; 3: 333-8.

9. Bakst R, Kovarik C, Werth VP. A case of localized scleroderma in a sculptor and his wife. J Clin Rheumatol 2009; 15: 399-401.

10. Brownell I, Soter NA, Franks AG Jr. Familial linear scleroderma (en coup de sabre) responsive to antimalarials and narrowband ultraviolet B therapy. Dermatol Online J 2007; 13: 11.

11. Lis-Święty A, Mierzwińska K, Wodok-Wieczorek K, et al. Coexistence of lichen sclerosus and localized scleroderma in female monozygotic twins. J Pediatr Adolesc Gynecol 2014; 27: 133-6.

12. Venneker GT, van Meegen M, de Kok-Nazaruk M, et al. Incomplete functional deficiencies of the fourth (C4) and second (C2) components of complement in a patient with linear 
frontoparietal scleroderma and his family. Deficiencies determined by a gene not linked to human leukocyte antigen system. Exp Clin Immunogenet 1996; 13: 104-11.

13. Iranzo P, López I, Palau J, et al. Morphoea in three siblings. J Eur Acad Dermatol Venereol 2001; 15: 46-7.

14. Kaur V, Singh G. Linear scleroderma in a family. Indian J Dermatol Venereol Leprol 1993; 59: 15-6.

15. Bunker CB, Atherton D, Tsioupra K, et al. Familial Raynaud's phenomenon and localized scleroderma associated with essential telangiectasia and cytogenetic abnormalities. J R Soc Med 1990; 83: 531-2.

16. Burge KM, Perry HD, Stickler GB. "Familial” scleroderma. Arch Dermatol 1969; 99: 681-7.

17. De Keyser F, Peene I, Joos R, et al. Occurrence of scleroderma in monozygotic twins. J Rheumatol 2000; 27: 2267-9.

18. Hulsmans RF, Asghar SS, Siddiqui AH, et al. Hereditary deficiency of C2 in association with linear scleroderma 'en coup de sabre'. Arch Dermatol 1986; 122: 76-9.

19. Patrizi A, Marzaduri S, Marini R. A familial case of scleroderma en coup de sabre. Acta Derm Venereol 2000; 80: 237.

20. Toyama S, Sato S, Asano Y. Localized scleroderma manifesting with skin lesions associated with mechanical stress. Eur J Dermatol 2019; 29: 439-40.

21. Zulian F. Scleroderma in children. Best Pract Res Clin Rheumatol 2017; 31: 576-95.

22. Rees RB, Bennett J. Localized scleroderma in father and daughters. AMA Arch Derm Syphilol 1953; 68: 360.

23. Christianson HB, Dorsey CS, O'Lary PA. Localized scleroderm. A clinical study of two hundred thirty-five cases. Arch Dermatol 1956; 74: 629-39.

24. Szczepanski A, Jakubowicz K. W sprawie rodzinnego występowania twardziny. Dermatol Rev 1972; 59: 361-4.

25. Taj M, Ahmad A. Familial localized scleroderma (morphea). Arch Dermatol 1977; 113: 1132-3.

26. Wadud MA, Bose BK, Al Nasir T. Familial localised scleroderma from Bangladesh: two case reports. Bangladesh Med Res Counc Bull 2006; 15: 15-9.

27. Manolios N, Dunckley H, Chivers T, et al. Immunogenetic analysis of 5 families with multicase occurrence of scleroderma and/or related variants. J Rheumatol 1995; 22: 85-92.

28. Pham CM, Browning JC. Morphea affecting a father and son. Pediatr Dermatol 2010; 27: 536-7. 